\title{
A novel approach for honey pollen profile assessment using an electronic tongue and chemometric tools
}

\author{
Luís G. Dias ${ }^{\text {a, b, }}{ }^{* *}$, Ana C.A. Veloso ${ }^{\text {c, d }}$, Mara E.B.C. Sousa ${ }^{\mathrm{e}}$, Letícia Estevinho ${ }^{\mathrm{e}}$, \\ Adélio A.S.C. Machado ${ }^{\mathrm{f}}$, António M. Peres ${ }^{\mathrm{g}}$ ** \\ a Escola Superior Agrária, Instituto Politécnico de Bragança, Campus Santa Apolónia, 5301-855 Bragança, Portugal

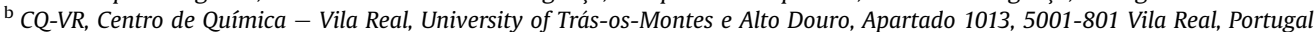 \\ ${ }^{c}$ Instituto Politécnico de Coimbra, ISEC, DEQB, Rua Pedro Nunes, Quinta da Nora, 3030-199 Coimbra, Portugal \\ d CEB-Centre of Biological Engineering, University of Minho, Campus de Gualtar, 4710-057 Braga, Portugal \\ e CIMO-Escola Superior Agrária, Instituto Politécnico de Bragança, Campus Santa Apolónia, 5301-855 Bragança, Portugal \\ ${ }_{\mathrm{f}}^{\mathrm{f}}$ LAQUIPAI - Laboratório de Química Inorgânica Pura e de Aplicação Interdisciplinar, Departamento de Química, Faculdade de Ciências da, Universidade do \\ Porto, Rua Campo Alegre $n^{\circ}$. 687, 4169-007 Porto, Portugal \\ ${ }^{g}$ LSRE-Laboratory of Separation and Reaction Engineering-Associate Laboratory LSRE/LCM, Escola Superior Agrária, Instituto Politécnico de Bragança, \\ Campus Santa Apolónia, 5301-855 Bragança, Portugal
}

\section{H I G H L I G H T S}

- Honey's floral origin labeling is a legal requirement.

- Melissopalynology analysis usually used to evaluate pollens profile is laborious.

- A novel E-tongue based approach is applied to assess pollens relative abundance.

- MLR models using SA variable selection and repeated K-fold crossvalidation.

- The approach may be used as a preliminary tool for pollinic evaluation.

\section{A R T I C L E I N F O}

\section{Article history:}

Received 22 November 2014

Received in revised form

3 March 2015

Accepted 21 October 2015

Available online 24 October 2015

\section{Keywords:}

Electronic tongue

Multiple linear regression models

Simulated annealing algorithm

Honey

Pollen profile
G R A P H I C A L A B S T R A C T

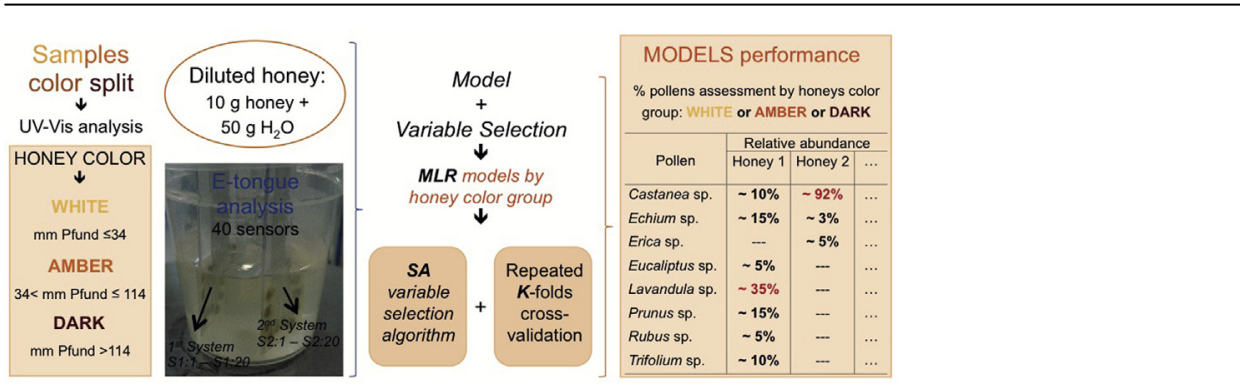


envisage its applicability for honey labeling and geographical origin identification. Nevertheless, this approach is not a full alternative to the traditional melissopalynologic analysis; it may be seen as a practical complementary tool for preliminary honey floral classification, leaving only problematic cases for pollinic evaluation.

\section{Introduction}

Honey is a very complex natural product that contains sugars, organic acids, amino acids, proteins, minerals, vitamins, lipids, aroma compounds, flavonoids, vitamins, pigments, waxes, pollen grains, enzymes and other phytochemicals [1-3]. Honey distinct and unique flavor, aroma, color and composition depend on a lot of variables: nectar composition of the flora source, bees' species, climate, environmental and seasonal conditions, agricultural practices, geographical origin as well as of the techniques used during honey extraction and storage [3-9]. The occurrence of pollen grains in honey can be explained either by their presence in the floral nectar or due to exogenous sources [10,11]. Honey pollen profile reflects forest vegetation, floral diversity and species composition of the plants foraged by honey bees. The relative pollen frequency is used for label purposes and to guarantee the geographical origin, factors that greatly influence honey's commercial value, being also used as a traceability tool by food control institutions [10,12]. Honeys may be classified as monofloral or polyfloral depending on whether a dominating pollen grain, originated from only one particular plant (monofloral honey) or no dominant pollen type in the sample (polyfloral honey) is found [8]. Monofloral honeys are usually more expensive and appreciated than polyfloral honeys [13-16]. Nevertheless, polyfloral honeys may contain higher levels of flavonoid and phenolic compounds than monofloral honey [17], therefore providing higher antioxidant activity. In fact, honey consumption may lead to potential health benefits due to the antioxidant and antimicrobial properties of honey $[17,18]$. Some studies $[17,19]$ report a positive correlation between honey color intensity and phenolic or flavonoid contents, and consequently antimicrobial activity. Also, it has been described that dark colored honeys show, in general, higher phenolic levels and antioxidant activity than light colored honeys [17,20-22]. However, consumers still prefer lighter honeys mainly due to the smooth sensory attributes $[13,23,24]$. In summary, honey color classification is also of major concern, not only since physico-chemical, sensory and healthy attributes may differ from light to dark honeys, but also due to consumer's preference. Usually, honey color is evaluated using a qualitative level scale [25], ranging from extra-white to dark amber, which is established by applying a millimeter Pfund scale calculated from the absorbance values recorded, at a specific wavelength $(625 \mathrm{~nm})$, from an aqueous diluted solution of honey. For honey floral classification, traditionally a melissopalynology analysis is used. This method consists of counting down the number of pollens grains of a honey sample and calculating the respective percentages of nectariferous pollens. These are then used to identify the botanical origin and the overall pollen spectrum, which may allow determining the geographical origin of honeys [12]. This technique is quite laborious, time-consuming and requires a high-skilled and trained technician. Nevertheless, so far no alternative or complementary analytical methodology has been reported for honey's pollinic analysis.

In the last years several studies reported the application of potentiometric electronic tongues for the classification of honeys according to botanical or geographical origins [13,14,26-30]. The successful results achieved may be explained by the variations found in honeys with different pollinic profiles (including monofloral to polyfloral honeys) and colors (white, amber and dark), which usually exhibit different sensory attributes, leading to overall different taste perception.

In this work, a novel quantitative application of a potentiometric E-tongue is evaluated, namely its potential use for assessing the relative abundance of the main pollens identified in Portuguese monofloral and polyfloral honeys: e.g., Echium sp., Erica sp., Eucaliptus sp., Lavandula sp., Prunus sp., Rubus sp. and Trifolium sp. The procedure includes a preliminary step where honey samples are split according to three main color groups (white, amber and dark), as suggested in a previous work [13]. Then, multiple linear regression models, based on the best sub-sets of electrochemical sensors (E-tongue), selected using a simulated annealing (SA) algorithm, are established, for the first time, to estimate pollen relative frequencies, using a repeated $\mathrm{K}$-fold cross-validation procedure to reduce the possible risk of overoptimistic fitting. Finally, based on the predicted pollens relative percentage abundance, the capability of correctly classify each honey according to its floral origin as monofloral or polyfloral honey was also evaluated. The work carried out aimed to verify the potential of merging electronic tongue data and chemometric tools, as a novel approach for the quantification of pollens relative abundances in honeys, reducing the use of the traditional time-consuming melissopalynology analysis.

\section{Materials and methods}

\subsection{Reagents}

All the reagents used were of analytical grade and used as purchased. For pollinic analysis the following reagents were used: anhydride acetic (Panreac), sulfuric acid (M\&B), acetic acid (Merck), $\mathrm{KOH}$ solution (Merck), fuchsin solution (Merck) and glycerine (Absolve). For construction of the electronic tongue the following reagents from Fluka were used as purchased: octadecylamine, oleyl alcohol, methyltrioctylammonium chloride and oleic acid as additives; bis(1-butylpentyl)adipate, dibutylsebacate, 2-nitrophenyloctyl-ether, tris(2-ethylhexyl)phosphate, dioctyl phenylphosphonate as plasticizers; and, poly(vinyl chloride) polymer (PVC).

\subsection{Honey samples: color and pollinic analysis}

Portuguese honeys, collected during 2010 and 2011 throughout the main honey production regions, kindly supplied by Federação Nacional de Apicultores de Portugal (FNAP), were studied. All 89 honey samples were analyzed and classified according to color and pollinic profile. The color of each sample was determined according to the quantitative millimeter Pfund (mmPfund) scale, calculated from absorbance data of aqueous diluted honey samples $(635 \mathrm{~nm}$, UV/vis spectrophotometer - Jenway, Genova model) according to [31]: 


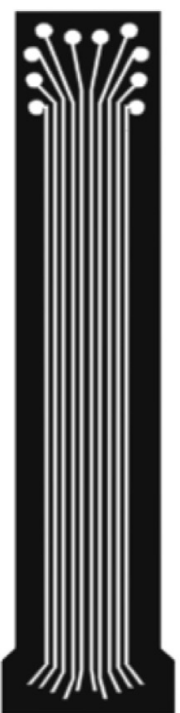

PVC board covered by a sticker with the multi-sensors scheme.
Epoxy conductive silver paste (EPO-TK E4110) mixed with hardener reagent.
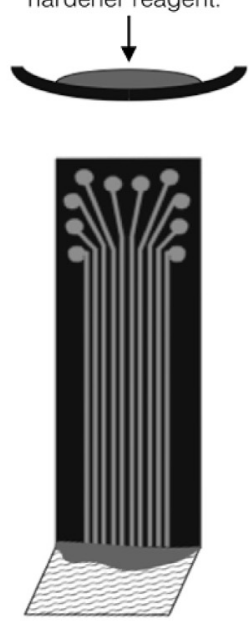

Multi-sensor system: application of the mixed conductive paste by printscreen technique and cured overnight at $40^{\circ} \mathrm{C}$.

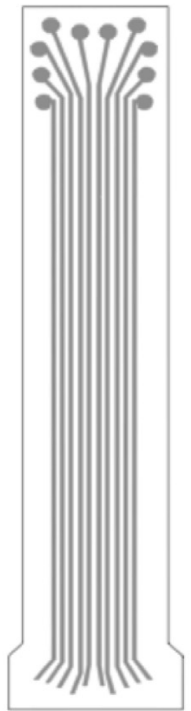

Printed

circuit system after sticker removal.

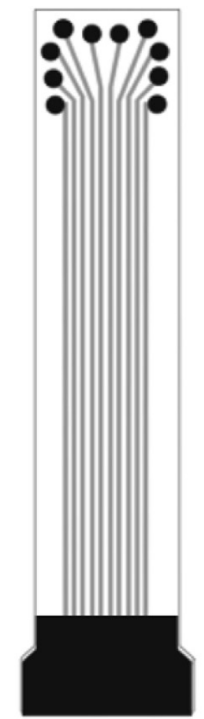

Dots where sensors will be placed and the RS-232 pin 25 male plug were protected before waterproofing the system.

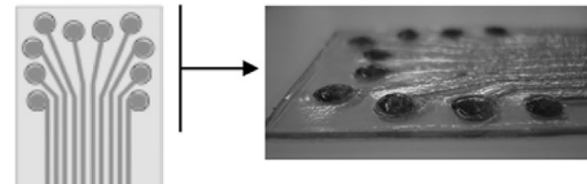

Lipid polymeric membranes were hydrated overnight before, analysis.
The system was waterproofed using an acrylic resin (PLASTIK 70) and let to dry.

The process was repeated 5 times.

Black covers were removed.

In each dot a polymeric membrane (plasticizer + additive mixture) was applied by the drop-by-drop technique.

Fig. 1. E-tongue construction: step by step process followed to build the proposed multisensor-array device.

$$
\text { mmPfund }=-3780+37.139 \times \text { Absorbance }
$$

The mmPfund were then transformed into a three-level qualitative color classification (white: mmPfund $\leq 34$; amber: $34<\operatorname{mmPfund} \leq 114$; and, dark: mmPfund $>114$ ), as proposed previously by Sousa et al. [13], based on the seven-level color scale defined by the United States Department of Agriculture [25].
The honey pollen quantitative spectrum analysis was conducted according to the method reported by Louveaux et al. [32]. Briefly, $10 \mathrm{~g}$ of honey were diluted with $30 \mathrm{~mL}$ of distilled water, followed by centrifugation ( $1500 \mathrm{rpm}, 30 \mathrm{~min}$ ) to concentrate the sediment, to which was added $10.0 \mathrm{~mL}$ of mixture $(9: 1, \mathrm{v} / \mathrm{v})$ containing anhydride acetic (Panreac) and sulfuric acid (M\&B). The solution was incubated under agitation in a water bath $\left(100{ }^{\circ} \mathrm{C}, 3 \mathrm{~min}\right)$, after 
which, it was centrifuged again and the solution decanted, being added $12.0 \mathrm{~mL}$ of acetic acid (Merck) to the sediment, followed by a new centrifugation/decantation procedure. The sediment was washed and re-suspended in $12.0 \mathrm{~mL}$ of distilled water, being centrifuged and decanted once again. A final wash step was carried out with $12.0 \mathrm{~mL}$ of $\mathrm{KOH}$ solution (7\%, Merck). After centrifugation and decantation process, the pollen grains recovered were finally stained (fuchsin solution (Merck) and mixed with glycerine (Absolve)). An optic microscope (Leitz Messtechnik GmbH, Wetzlar, Germany) with two objectives $(400 \times$ and $1000 \times$ ) was used, by a trained technician of the research team, to identify and count the pollen grains (a minimum of 1000 grains were counted), using pollen morphology reference standards available at the Microbiology Laboratory of Escola Superior Agrária - Instituto Politécnico de Bragança. Honeys were classified as monofloral or polyfloral based on their floral origin, type, presence/absence and relative abundance of nectariferous pollens.

\subsection{Electronic tongue apparatus and analysis}

The potentiometric multisensor device (E-tongue) included two print-screen arrays, each containing 20 chemical lipid membranes ( $3 \%$ of lipidic additive, $65 \%$ of plasticizer and $32 \%$ of PVC), prepared using the drop-by-drop technique. Fig. 1 exemplifies the building steps followed for the construction of the multi-sensor device. The types of cross-sensitivity sensors and their relative compositions were chosen based on a previous work [33], enabling good signal temporal stability (\%RSD $<5 \%$ ) and repeatability $(0.5 \%<\%$ RSD $<15 \%$ ) towards sweet, acid, bitter, salty and umami basic standard taste compounds. Further details on membrane composition of each sensor can be found in Sousa et al. [13]. These membranes contain hydrophobic and hydrophilic groups that enable electrostatic or hydrophobic interactions [34] in the presence of nonelectrolytes and electrolytes substances [35-39]. As previously [13], the sensors were identified with a letter $S$ (for sensor), followed by the number of the array (1 or 2 ) and the number of the membrane (1-20), comprising 20 sensors and replicas. Details regarding each sensor composition (plasticizer and additive combinations) can be found in Table 1. For signals acquisition $(-1.0 \mathrm{~V}$ to $+1.0 \mathrm{~V})$, a multiplexer Agilent Data Acquisition
Switch Unit model 34970A, controlled with the Agilent BenchLink Data Logger software installed on a PC, was used, together with an $\mathrm{Ag} / \mathrm{AgCl}$ reference electrode (Crison, 5241). Samples were analyzed directly, after honey dilution with deionized water $(\mathrm{pH} \approx 6)$, by mixing $10.0 \mathrm{~g}$ of honey with $50.0 \mathrm{~g}$ of water. No other reagent was added to the solution. Moreover, all assays were carried out at ambient temperature enabling reducing the analysis time of each honey sample. Finally, to minimize potentiometric signals drift, all samples were analyzed in a 14 -h period.

\subsection{Statistical analysis}

Multiple linear regression (MLR) models were established to calculate the relative abundance (in percentage) of the main pollens identified by pollinic analysis, in the 89 different honeys evaluated. MLR models were developed for each color group (white, amber and dark honeys), based on the most informative sub-sets of sensors (between 2 and 39 sensors, which must be lower than the number of samples under study) selected from the independent signals of the 40 potentiometric sensors contained in the E-tongue. As known, MLR models may be used when more than one predictor is available, allowing correlating a dependent variable, $Y_{i}$ (e.g., where $Y$ represents the pollen percentage in each honey sample for the type of pollen $i$ ) with two or more independent variables, $X_{i, j}$ (in this case, the letter $X$ stands for the potential signal of each sensor recorded for honey samples containing the type of pollen $i$ and the index $j$ represent the identification code number of the sensor, that varies between 1 and 40, which is the total number of potentiometric sensors) according to the equation:

$Y_{i}=\alpha+\sum_{j=1}^{n}\left(\beta_{j} \times X_{i, j}\right)+\varepsilon_{i}$

where, $\alpha$ is the intercept, $\beta_{j}$ are the coefficients and $\varepsilon_{i}$ is the error for each MLR model established. Independent variable selection (among the 40 sensor signals) was carried out using the metaheuristic SA algorithm [40-42] with the aim of establishing MLR models with the minimum number of sensors. The SA algorithm seeks to select the optimal conditions based on the annealing physic process. This process involves a heating step followed by a

Table 1

E-tongue sensors: identification of the plasticizer and additive compounds used in each lipidic-polymeric membrane

\begin{tabular}{|c|c|c|}
\hline Sensor ID no ${ }^{a}$ & Plasticizer compound ${ }^{\mathrm{b}}(65 \%)$ & Additive compound ${ }^{\mathrm{C}}(3 \%)$ \\
\hline $\mathrm{S} 1: 1$ or $\mathrm{S} 2: 1$ & \multirow[t]{4}{*}{ Bis(1-butylpentyl) adipate $\left(\left[-\left(\mathrm{CH}_{2}\right)_{2} \mathrm{COOCH}\left[\left(\mathrm{CH}_{2}\right)_{3} \mathrm{CH}_{3}\right]_{2}\right]_{2}\right)$} & Octadecylamine $\left(\mathrm{CH}_{3}\left(\mathrm{CH}_{2}\right)_{17} \mathrm{NH}_{2}\right)$ \\
\hline $\mathrm{S} 1: 2$ or $\mathrm{S} 2: 2$ & & Oleyl alcohol $\left(\mathrm{CH}_{3}\left(\mathrm{CH}_{2}\right)_{7} \mathrm{CH}=\mathrm{CH}\left(\mathrm{CH}_{2}\right)_{7} \mathrm{CH}_{2} \mathrm{OH}\right)$ \\
\hline $\mathrm{S} 1: 3$ or $\mathrm{S} 2: 3$ & & Methyltrioctylammonium chloride $\left(\left[\mathrm{CH}_{3}\left(\mathrm{CH}_{2}\right)_{6} \mathrm{CH}_{2}\right]_{3} \mathrm{~N}(\mathrm{Cl}) \mathrm{CH}_{3}\right)$ \\
\hline $\mathrm{S} 1: 4$ or $\mathrm{S} 2: 4$ & & Oleic acid $\left(\mathrm{CH}_{3}\left(\mathrm{CH}_{2}\right)_{7} \mathrm{CH}=\mathrm{CH}\left(\mathrm{CH}_{2}\right)_{7} \mathrm{COOH}\right)$ \\
\hline $\mathrm{S} 1: 5$ or $\mathrm{S} 2: 5$ & \multirow[t]{4}{*}{ Dibutyl sebacate $\left(\left[-\left(\mathrm{CH}_{2}\right)_{4} \mathrm{CO}_{2}\left(\mathrm{CH}_{2}\right)_{3} \mathrm{CH}_{3}\right]_{2}\right)$} & Octadecylamine $\left(\mathrm{CH}_{3}\left(\mathrm{CH}_{2}\right)_{17} \mathrm{NH}_{2}\right)$ \\
\hline $\mathrm{S} 1: 6$ or $\mathrm{S} 2: 6$ & & Oleyl alcohol $\left(\mathrm{CH}_{3}\left(\mathrm{CH}_{2}\right)_{7} \mathrm{CH}=\mathrm{CH}\left(\mathrm{CH}_{2}\right)_{7} \mathrm{CH}_{2} \mathrm{OH}\right)$ \\
\hline $\mathrm{S} 1: 7$ or $\mathrm{S} 2: 7$ & & Methyltrioctylammonium chloride $\left(\left[\mathrm{CH}_{3}\left(\mathrm{CH}_{2}\right)_{6} \mathrm{CH}_{2}\right]_{3} \mathrm{~N}(\mathrm{Cl}) \mathrm{CH}_{3}\right)$ \\
\hline $\mathrm{S} 1: 8$ or $\mathrm{S} 2: 8$ & & Oleic acid $\left(\mathrm{CH}_{3}\left(\mathrm{CH}_{2}\right)_{7} \mathrm{CH}=\mathrm{CH}\left(\mathrm{CH}_{2}\right)_{7} \mathrm{COOH}\right)$ \\
\hline $\mathrm{S} 1: 9$ or $\mathrm{S} 2: 9$ & \multirow[t]{4}{*}{ 2-nitrophenyl-octyl ether $\left(\mathrm{O}_{2} \mathrm{NC}_{6} \mathrm{H}_{4} \mathrm{O}\left(\mathrm{CH}_{2}\right)_{7} \mathrm{CH}_{3}\right)$} & Octadecylamine $\left(\mathrm{CH}_{3}\left(\mathrm{CH}_{2}\right)_{17} \mathrm{NH}_{2}\right)$ \\
\hline $\mathrm{S} 1: 10$ or $\mathrm{S} 2: 10$ & & Oleyl alcohol $\left(\mathrm{CH}_{3}\left(\mathrm{CH}_{2}\right)_{7} \mathrm{CH}=\mathrm{CH}\left(\mathrm{CH}_{2}\right)_{7} \mathrm{CH}_{2} \mathrm{OH}\right)$ \\
\hline $\mathrm{S} 1: 11$ or $\mathrm{S} 2: 11$ & & Methyltrioctylammonium chloride $\left(\left[\mathrm{CH}_{3}\left(\mathrm{CH}_{2}\right)_{6} \mathrm{CH}_{2}\right]_{3} \mathrm{~N}(\mathrm{Cl}) \mathrm{CH}_{3}\right)$ \\
\hline $\mathrm{S} 1: 12$ or $\mathrm{S} 2: 12$ & & Oleic acid $\left(\mathrm{CH}_{3}\left(\mathrm{CH}_{2}\right)_{7} \mathrm{CH}=\mathrm{CH}\left(\mathrm{CH}_{2}\right)_{7} \mathrm{COOH}\right)$ \\
\hline $\mathrm{S} 1: 13$ or $\mathrm{S} 2: 13$ & \multirow[t]{4}{*}{ Tris(2-ethylhexyl) phosphate $\left(\left[\mathrm{CH}_{3}\left(\mathrm{CH}_{2}\right)_{3} \mathrm{CH}\left(\mathrm{C}_{2} \mathrm{H}_{5}\right) \mathrm{CH}_{2} \mathrm{O}\right]_{3} \mathrm{P}(\mathrm{O})\right)$} & Octadecylamine $\left(\mathrm{CH}_{3}\left(\mathrm{CH}_{2}\right)_{17} \mathrm{NH}_{2}\right)$ \\
\hline $\mathrm{S} 1: 14$ or $\mathrm{S} 2: 14$ & & Oleyl alcohol $\left(\mathrm{CH}_{3}\left(\mathrm{CH}_{2}\right)_{7} \mathrm{CH}=\mathrm{CH}\left(\mathrm{CH}_{2}\right)_{7} \mathrm{CH}_{2} \mathrm{OH}\right)$ \\
\hline $\mathrm{S} 1: 15$ or $\mathrm{S} 2: 15$ & & Methyltrioctylammonium chloride $\left(\left[\mathrm{CH}_{3}\left(\mathrm{CH}_{2}\right)_{6} \mathrm{CH}_{2}\right]_{3} \mathrm{~N}(\mathrm{Cl}) \mathrm{CH}_{3}\right)$ \\
\hline $\mathrm{S} 1: 16$ or $\mathrm{S} 2: 16$ & & Oleic acid $\left(\mathrm{CH}_{3}\left(\mathrm{CH}_{2}\right)_{7} \mathrm{CH}=\mathrm{CH}\left(\mathrm{CH}_{2}\right)_{7} \mathrm{COOH}\right)$ \\
\hline $\mathrm{S} 1: 17$ or $\mathrm{S} 2: 17$ & \multirow[t]{4}{*}{ Dioctyl phenylphosphonate $\left.\mathrm{C}_{6} \mathrm{H}_{5} \mathrm{P}(\mathrm{O})\left[\mathrm{O}\left(\mathrm{CH}_{2}\right)_{7} \mathrm{CH}_{3}\right]_{2}\right)$} & Octadecylamine $\left(\mathrm{CH}_{3}\left(\mathrm{CH}_{2}\right)_{17} \mathrm{NH}_{2}\right)$ \\
\hline $\mathrm{S} 1: 18$ or $\mathrm{S} 2: 18$ & & Oleyl alcohol $\left(\mathrm{CH}_{3}\left(\mathrm{CH}_{2}\right)_{7} \mathrm{CH}=\mathrm{CH}\left(\mathrm{CH}_{2}\right)_{7} \mathrm{CH}_{2} \mathrm{OH}\right)$ \\
\hline $\mathrm{S} 1: 19$ or $\mathrm{S} 2: 19$ & & Methyltrioctylammonium chloride $\left(\left[\mathrm{CH}_{3}\left(\mathrm{CH}_{2}\right)_{6} \mathrm{CH}_{2}\right]_{3} \mathrm{~N}(\mathrm{Cl}) \mathrm{CH}_{3}\right)$ \\
\hline $\mathrm{S} 1: 20$ or $\mathrm{S} 2: 20$ & & Oleic acid $\left(\mathrm{CH}_{3}\left(\mathrm{CH}_{2}\right)_{7} \mathrm{CH}=\mathrm{CH}\left(\mathrm{CH}_{2}\right)_{7} \mathrm{COOH}\right)$ \\
\hline
\end{tabular}

a Sensor identification number.

b All plasticizers were selectophore ${ }^{\mathrm{TM}}$ grade from Fluka, with purity $\geq 97 \%$.

c All additives were from Fluka, with purity $\geq 97 \%$. 


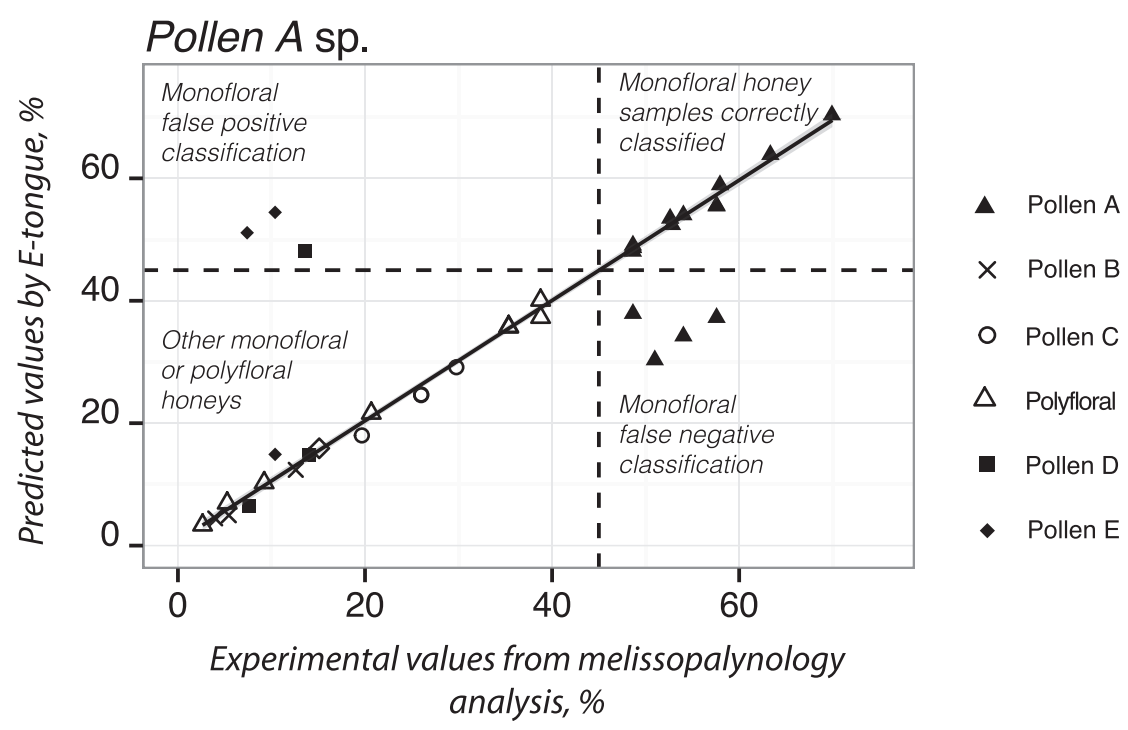

Fig. 2. Scheme showing the potential application of the novel quantitative E-tongue/MLR-SA approach for honey qualitative floral origin classification.

slow controlled cooling of a material (allowing to reach thermal equilibrium at each temperature) so that the material can reach the most regular possible crystal lattice configuration (free from defects at a minimum energy crystalline state). The SA algorithm is classified as a meta-heuristic algorithm, which is able to identify a subset of the original independent variables that corresponds to a global optimum for a given approximation criterion, selected within a large search space of other possible subsets of variables. In detail, the algorithm searches a global minimum for optimizing a system with $k$ variables. In each iteration, the values of two solutions (the current subset of variables $k$ and the new subset to be tested, also with $k$ variables) are compared by a test which measures the quality of those two subsets of variables. The new solution is randomly selected in the neighborhood of the current solution and tested according to the rules of simulated annealing, being selected the current solution if it gives best results than the initial one. The algorithm continues the search for new solutions till it reach the maximum number of attempts established at the beginning of the procedure. In general, 10,000 attempts are used to select the best subset of variables (best model), starting the process of selecting the best subsets of variables on each trial, thus ensuring a greater confidence in finding a true optimal solution [40,41]. In the present study, for each sub-set of sensors under evaluation (combinations of sensors from 2 to 39), the set of sensors chosen for each possible combination was the one that enabled to obtain the maximum value of the tau 2 quality criterion, which can be used as a measure of the goodness of fitting, since for a univariate MLR, tau2 is the standard coefficient of determination $\left(R^{2}\right)[40,41]$. Leave-oneout cross validation (LOO-CV) is usually applied when it is not possible to use an independent external validation group due to the

Table 2

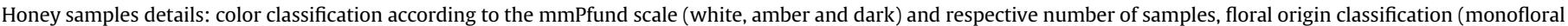
and polyfloral) based on the pollinic analysis, type of identified pollens, number of honey containing a specific kind of pollen and its relative abundance.

\begin{tabular}{|c|c|c|c|c|c|}
\hline Honey color (mmPfund) & Total of honeys & Floral classification & Identified pollens & No of honeys with a specific pollen ${ }^{a}$ & Pollen relative abundance (\%) \\
\hline \multirow[t]{8}{*}{ White (15.9-33.4) } & \multirow[t]{8}{*}{22} & \multirow[t]{8}{*}{22 monofloral and 0 polyfloral } & Castanea sp. & 6 & $2.5 \%-19.3 \%$ \\
\hline & & & Echium sp. & 20 & $3.8 \%-79.2 \%$ \\
\hline & & & Erica sp. & 4 & $2.7 \%-12.0 \%$ \\
\hline & & & Eucaliptus sp. & 6 & $2.1 \%-82.0 \%$ \\
\hline & & & Lavandula sp. & 20 & $2.7 \%-66.5 \%$ \\
\hline & & & Prunus sp. & 14 & $2.5 \%-22.3 \%$ \\
\hline & & & Rubus sp. & 19 & $2.8 \%-38.5 \%$ \\
\hline & & & Trifolium sp. & 9 & $2.4 \%-81.7 \%$ \\
\hline \multirow[t]{8}{*}{ Amber (34.8-113.4) } & \multirow[t]{8}{*}{42} & \multirow[t]{8}{*}{32 monofloral and 10 polyfloral } & Castanea sp. & 26 & $3.0 \%-64.1 \%$ \\
\hline & & & Echium sp. & 31 & $1.4 \%-70.0 \%$ \\
\hline & & & Erica sp. & 17 & $1.2 \%-13.9 \%$ \\
\hline & & & Eucaliptus sp. & 17 & $1.5 \%-72.2 \%$ \\
\hline & & & Lavandula sp. & 29 & $1.2 \%-45.6 \%$ \\
\hline & & & Prunus sp. & 36 & $1.6 \%-80.1 \%$ \\
\hline & & & Rubus sp. & 34 & $2.8 \%-68.6 \%$ \\
\hline & & & Trifolium sp. & 25 & $1.4 \%-69.0 \%$ \\
\hline \multirow[t]{8}{*}{ Dark (114.7-204.2) } & \multirow[t]{8}{*}{25} & \multirow[t]{8}{*}{20 monofloral and 5 polyfloral } & Castanea sp. & 24 & $5.9 \%-94.8 \%$ \\
\hline & & & Echium sp. & 14 & $2.6 \%-54.6 \%$ \\
\hline & & & Erica sp. & 16 & $1.3 \%-81.7 \%$ \\
\hline & & & Eucaliptus sp. & 12 & $1.2 \%-7.5 \%$ \\
\hline & & & Lavandula sp. & 14 & $1.2 \%-17.1 \%$ \\
\hline & & & Prunus sp. & 17 & $1.4 \%-48.5 \%$ \\
\hline & & & Rubus sp. & 15 & $1.1 \%-60.7 \%$ \\
\hline & & & Trifolium sp. & 11 & $1.5 \%-57.6 \%$ \\
\hline
\end{tabular}

\footnotetext{
a Only considered, for modeling purposes, if the number of honeys was greater than 10 .
} 

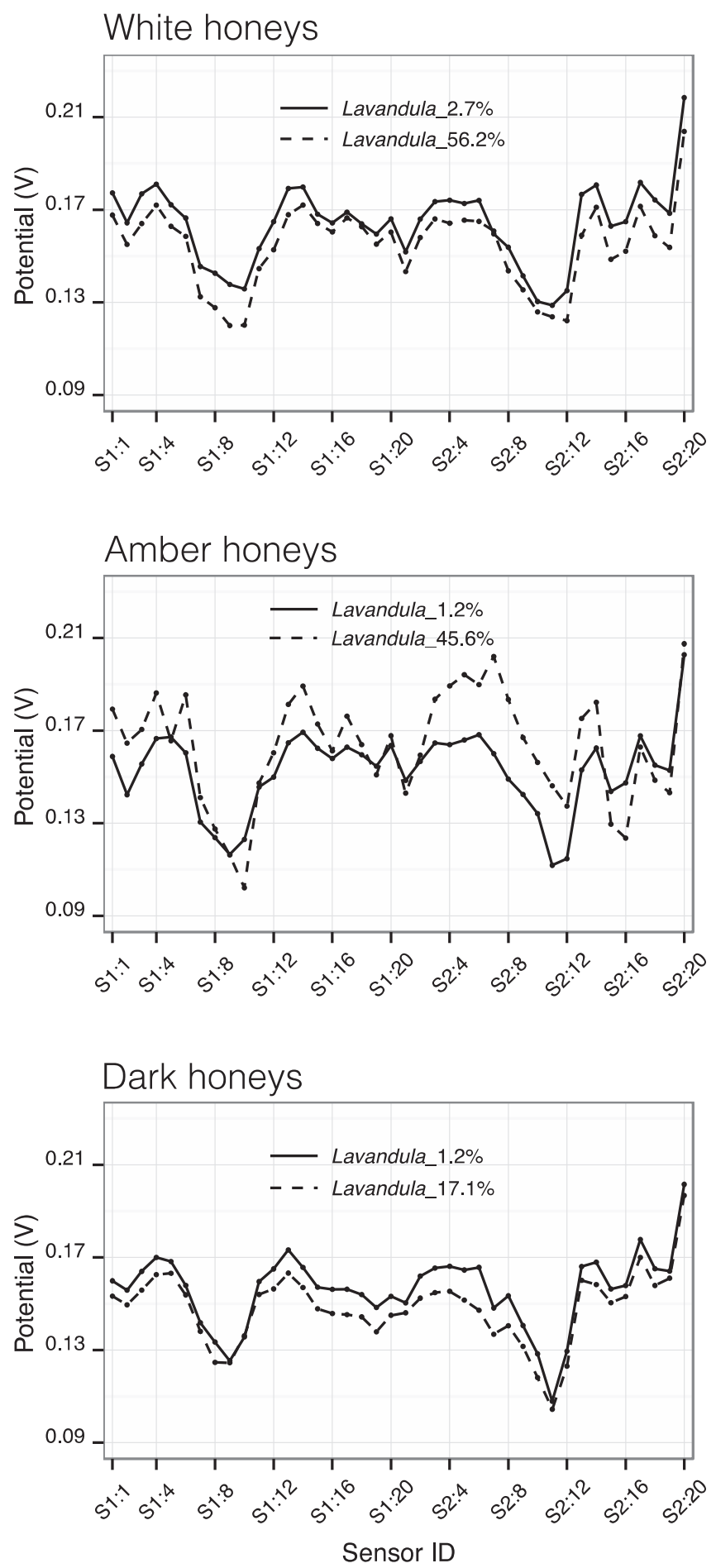

Fig. 3. E-tongue potentiometric signals profiles recorded for white, amber or dark honey samples containing minimum and maximum relative percentage abundance of Lavandula sp. pollen.

reduce dimension of the dataset. This procedure has been previously used for testing qualitative and quantitative predictive models [43-45]. However, it is still considered an overoptimistic approach and so, in this work, to minimize the potential risk of obtaining overfitted predictive MLR models, a K-fold crossvalidation strategy was applied to the sub-sets of sensors chosen by the SA algorithm. For this purpose, data was divided into $\mathrm{K}$ subsets, approximately of equal size, and K models were fitted, each time considering K-1 subsets, as the training set, leaving out one of the subsets, which was used as the validation set, to compute the predictive error for the obtained model [46]. Although there is no formal rule to select the number of K-folds, a possibility is to fix a value that allows the formation of subsets with $10-20 \%$ of data, which enables bias reduction. Also, to reduce the uncertainty of the estimates, a repeated K-fold cross-validation procedure is usually used, being in this work the number of repetitions set equal to 10 . This procedure was implemented to select a sub-set of E-tongue sensors that enabled establishing a linear relation between predicted percentages of a specific type of pollen in honey versus their true percentages obtained from melissopalynological analysis (used as the standard method), with a minimum average $R^{2}$ value of 0.90 and the minimum number of sensors. The predictive quantitative performance of the MLR model was further evaluated by testing if the slope and intercept values of the linear relation between predicted pollen relative percentage by the E-tongue and the experimental pollen abundance data were equal to the theoretical expected values (one and zero, respectively), from a statistical point of view [47]. Also, this graphical representation may allow verifying which honeys were correctly classified according to their floral origin by the MLR models and the possible occurrence of false positive or false negative classifications. Indeed, as exemplified in Fig. 2, four situations may occur when the MLR models are used to quantify the percentage of a specific type of pollen in honey samples: (i) if the samples fail into the upper right quadrant they would be correctly classified as monofloral in that pollen; (ii) if the samples are located in the upper left quadrant would be misclassified as monofloral (false positive cases); (iii) if samples are within the low left quadrant they may be correctly classified as polyfloral or monofloral in other type of pollen; and, (iv) if samples are located in the low right quadrant they are not correctly classified as monofloral in that pollen (false negative cases). All statistical data analysis was performed using the Subselect [40,41] and MASS [48] packages of the open source statistical program $R$ (version 2.15.1), at $5 \%$ of significance level.

\section{Results and discussion}

\subsection{Honey color classification, pollen profile and floral classification}

All the 89 different honeys were subjected to color and pollinic analysis. The results showed that honey colors varied from extrawhite to dark amber, according to the qualitative color scale [25]. The samples were grouped into 3 main color groups, as proposed previously [13], 22 white honeys, 42 amber honeys and 25 dark honeys, as described in Table 2. The melissopalynological assays of the studied honeys identified 8 main different pollens (Castanea sp., Echium sp., Erica sp., Eucaliptus sp., Lavandula sp., Prunus sp., Rubus sp. and Trifolium sp.), which relative abundance percentages varied from $1 \%$ to $95 \%$, resulting in 74 monofloral and 15 polyfloral honeys (Table 1). As can be seen in Table 1, for white honeys and 4 pollen species (Castanea sp., Erica sp., Eucaliptus sp. and Trifolium sp.), the number of samples was lower than 10 . For these cases, since the use of the repeated K-folds cross-validation procedure was not realistic (resulting in the application of an overoptimistic LOO-CV procedure), no MLR models were developed.

\subsection{E-tongue analysis}

The capability of using potentiometric sensor signals to quantify the relative percentage abundance of a specific pollen in a honey sample was evaluated. Indeed, the honey pollinic profile is correlated to the global honey chemical composition through a dependency with the quantity and type of flowers nectar collected by 
Table 3

Multiple linear regression (MLR) models parameters for each type of pollen (monofloral and/or polyfloral) and honey color group.

\begin{tabular}{|c|c|c|c|c|c|c|c|c|}
\hline \multirow[t]{2}{*}{ Pollen type } & \multirow[t]{2}{*}{ No. honeys with a specific pollen } & \multicolumn{7}{|c|}{ MLR model parameters for K-fold cross-validation procedure (K-folds $\times 10$ repeats) } \\
\hline & & No. K-folds & No. sensors ${ }^{* *}$ & Slope & Slope $\mathrm{Cl}^{* * *}$ & Intercept & Intercept $\mathrm{CI}^{\star \star \star \star}$ & Mean $R^{2}$ coefficient $\pm \mathrm{SD}$ \\
\hline \multicolumn{9}{|c|}{ White honeys (mmPfund $\leq 34$ ) } \\
\hline Castanea sp. & $6^{*}$ & - & - & - & - & - & - & - \\
\hline Echium sp. & 20 & 5 & $13^{\mathrm{c}}$ & 0.998 & {$[0.984,1.013]$} & 0.160 & {$[-0.449,0.770]$} & $0.99 \pm 0.02$ \\
\hline Erica sp. & $4^{*}$ & - & - & - & - & - & - & - \\
\hline Eucaliptus sp. & $6^{*}$ & - & - & - & - & - & - & - \\
\hline Lavandula sp. & 20 & 5 & $12^{\mathrm{j}}$ & 0.992 & {$[0.973,1.010]$} & -0.136 & {$[-0.760,0.489]$} & $0.99 \pm 0.02$ \\
\hline Prunus sp. & 14 & 5 & $8^{\mathrm{m}}$ & 0.980 & {$[0.957,1.003]$} & 0.077 & {$[-0.164,0.319]$} & $0.94 \pm 0.15$ \\
\hline Rubus sp. & 19 & 5 & $12^{\mathrm{p}}$ & 1.000 & {$[0.984,1.017]$} & 0.010 & {$[-0.282,0.302]$} & $0.99 \pm 0.02$ \\
\hline Trifolium sp. & $9^{*}$ & - & - & - & - & - & - & - \\
\hline \multicolumn{9}{|c|}{ Amber honeys (34 < mmPfund $\leq 114)$} \\
\hline Castanea sp. & 26 & 6 & $17^{\mathrm{a}}$ & 0.991 & {$[0.970,1.013]$} & 0.435 & {$[-0.054,0.925]$} & $0.96 \pm 0.08$ \\
\hline Echium sp. & 31 & 7 & $23^{\mathrm{d}}$ & 1.001 & {$[0.977,1.024]$} & 0.125 & {$[-0.762,1.012]$} & $0.97 \pm 0.10$ \\
\hline Erica sp. & 17 & 5 & $12^{\mathrm{f}}$ & 1.000 & {$[0.988,1.013]$} & -0.042 & {$[-0.119,0.036]$} & $0.996 \pm 0.010$ \\
\hline Eucaliptus sp. & 17 & 5 & $10^{\mathrm{h}}$ & 0.996 & {$[0.980,1.011]$} & 0.421 & {$[-0.033,0.876]$} & $0.99 \pm 0.03$ \\
\hline Lavandula sp. & 29 & 7 & $21^{\mathrm{k}}$ & 0.959 & {$[0.944,0.974]$} & 0.179 & {$[-0.058,0.412]$} & $0.98 \pm 0.05$ \\
\hline Prunus sp. & 36 & 9 & $28^{\mathrm{n}}$ & 1.017 & {$[0.987,1.046]$} & -0.198 & {$[-0.905,0.509]$} & $0.91 \pm 0.15$ \\
\hline Rubus sp. & 34 & 8 & $26^{\mathrm{q}}$ & 0.999 & {$[0.965,1.033]$} & -0.626 & {$[-1.756,0.505]$} & $0.95 \pm 0.08$ \\
\hline Trifolium sp. & 24 & 6 & $16^{\mathrm{s}}$ & 1.011 & {$[0.994,1.028]$} & -0.347 & {$[-0.670,-0.025]$} & $0.98 \pm 0.04$ \\
\hline \multicolumn{9}{|c|}{ Dark honeys (mmPfund > 114) } \\
\hline Castanea sp. & 24 & 6 & $13^{\mathrm{b}}$ & 0.977 & {$[0.946,1.008]$} & 1.456 & {$[-0.055,2.968]$} & $0.96 \pm 0.05$ \\
\hline Echium sp. & 14 & 5 & $8^{e}$ & 1.003 & {$[0.992,1.014]$} & -0.067 & {$[-0.315,0.181]$} & $0.99 \pm 0.02$ \\
\hline Erica sp. & 16 & 5 & $9^{g}$ & 1.009 & {$[0.989,1.028]$} & 0.358 & {$[-0.476,1.191]$} & $0.99 \pm 0.01$ \\
\hline Eucaliptus sp. & 12 & 5 & $6^{\mathrm{i}}$ & 1.003 & {$[0.967,1.040]$} & 0.033 & {$[-0.126,0.192]$} & $0.99 \pm 0.03$ \\
\hline Lavandula sp. & 14 & 5 & $8^{1}$ & 0.999 & {$[0.981,1.016]$} & 0.107 & {$[-0.001,0.216]$} & $0.94 \pm 0.13$ \\
\hline Prunus sp. & 17 & 5 & $12^{\circ}$ & 1.004 & {$[0.996,1.012]$} & 0.034 & {$[-0.087,0.155]$} & $0.99 \pm 0.06$ \\
\hline Rubus sp. & 15 & 5 & $9^{r}$ & 1.005 & {$[0.992,1.018]$} & -0.114 & {$[-0.462,0.233]$} & $0.995 \pm 0.008$ \\
\hline Trifolium sp. & 11 & 5 & $6^{\mathrm{t}}$ & 0.996 & {$[0.976,1.016]$} & -0.014 & {$[-0.411,0.384]$} & $0.97 \pm 0.12$ \\
\hline
\end{tabular}

*If less than 10 samples were available no MLR models were developed.

${ }^{* *}$ Number of sensors selected using the SA meta-heuristic variable selection algorithm.

${ }^{* * *}$ Slope CI: slope's $95 \%$ confidence interval.

${ }^{* * * *}$ Intercept $\mathrm{CI}$ : intercept's $95 \%$ confidence interval.

a S1:1, S1:3, S1:6, S1:10, S1:13, S1:19, S1:20, S2:6, S2:8-S2:11, S2:14-S2:17, S2:19.

b $\mathrm{S} 1: 1, \mathrm{~S} 1: 8, \mathrm{~S} 1: 9, \mathrm{~S} 1: 11, \mathrm{~S} 1: 13-\mathrm{S} 1: 15, \mathrm{~S} 1: 17, \mathrm{~S} 1: 20, \mathrm{~S} 2: 2, \mathrm{~S} 2: 4, \mathrm{~S} 2: 9, \mathrm{~S} 2: 13$.

c S1:6, S1:10, S1:11, S1:13, S1:16, S1:19, S1:20, S2:2, S2:3, S2:7, S2:8, S2:12, S2:13.

d S1:3, S1:4, S1:6- S1:8, S1:10, S1:12, S1:14, S1:15, S1:17-S1:20, S2:1, S2:2, S2:5, S2:10-S2:13, S2:16, S2:18, S2:19.

e $\mathrm{S} 1: 10, \mathrm{~S} 1: 11, \mathrm{~S} 1: 14, \mathrm{~S} 1: 17, \mathrm{~S} 2: 3, \mathrm{~S} 2: 6, \mathrm{~S} 2: 18, \mathrm{~S} 2: 19$.

f $\mathrm{S} 1: 6, \mathrm{~S} 1: 8, \mathrm{~S} 1: 12, \mathrm{~S} 1: 13, \mathrm{~S} 2: 2, \mathrm{~S} 2: 4, \mathrm{~S} 2: 7, \mathrm{~S} 2: 9, \mathrm{~S} 2: 11, \mathrm{~S} 2: 14, \mathrm{~S} 2: 15, \mathrm{~S} 2: 20$.

g S1:6, S1:10, S1:14, S1:15, S1:19, S1:20, S2:14, S2:16, S2:20.

h $\mathrm{S} 1: 3, \mathrm{~S} 1: 5, \mathrm{~S} 1: 12, \mathrm{~S} 1: 14, \mathrm{~S} 1: 16, \mathrm{~S} 1: 18, \mathrm{~S} 2: 2, \mathrm{~S} 2: 10, \mathrm{~S} 2: 11, \mathrm{~S} 2: 18$

i $\mathrm{S} 1: 8, \mathrm{~S} 2: 4, \mathrm{~S} 2: 5, \mathrm{~S} 2: 17-\mathrm{S} 2: 19$

j $\mathrm{S} 1: 3, \mathrm{~S} 1: 5, \mathrm{~S} 1: 6, \mathrm{~S} 1: 16, \mathrm{~S} 1: 19, \mathrm{~S} 2: 7, \mathrm{~S} 2: 9, \mathrm{~S} 2: 10, \mathrm{~S} 2: 14-\mathrm{S} 2: 16, \mathrm{~S} 2: 18$.

k $\mathrm{S} 1: 1, \mathrm{~S} 1: 3, \mathrm{~S} 1: 4, \mathrm{~S} 1: 9, \mathrm{~S} 1: 12-\mathrm{S} 1: 15, \mathrm{~S} 1: 18-\mathrm{S} 1: 20, \mathrm{~S} 2: 2, \mathrm{~S} 2: 4, \mathrm{~S} 2: 10-\mathrm{S} 2: 13, \mathrm{~S} 2: 15, \mathrm{~S} 2: 16, \mathrm{~S} 2: 18, \mathrm{~S} 2: 20$.

${ }^{1} \mathrm{~S} 1: 2, \mathrm{~S} 1: 3, \mathrm{~S} 1: 10, \mathrm{~S} 1: 11, \mathrm{~S} 2: 1, \mathrm{~S} 2: 4, \mathrm{~S} 2: 6, \mathrm{~S} 2: 9$.

m $\mathrm{S} 1: 2, \mathrm{~S} 1: 3, \mathrm{~S} 1: 14-\mathrm{S} 1: 16, \mathrm{~S} 1: 19, \mathrm{~S} 2: 10, \mathrm{~S} 2: 12$.

n S1:1-S1:3, S1:5-S1:11, S1:13-S1:15, S1:18, S1:19, S2:1, S2:2, S2:4, S2:7-S2:10, S2:13-S2:15, S2:17-S2:19.

o S1:2, S1:5, S1:8, S1:9, S1:13, S1:17, S1:20, S2:6, S2:9, S2:13, S2:17, S2:18.

p $\mathrm{S} 1: 1, \mathrm{~S} 1: 2, \mathrm{~S} 1: 4-\mathrm{S} 1: 6, \mathrm{~S} 1: 8, \mathrm{~S} 1: 11, \mathrm{~S} 1: 14, \mathrm{~S} 1: 16, \mathrm{~S} 1: 18, \mathrm{~S} 2: 1, \mathrm{~S} 2: 20$.

q $\mathrm{S} 1: 1, \mathrm{~S} 1: 2, \mathrm{~S} 1: 4-\mathrm{S} 1: 8, \mathrm{~S} 1: 11, \mathrm{~S} 1: 13-\mathrm{S} 1: 17, \mathrm{~S} 1: 19, \mathrm{~S} 2: 3, \mathrm{~S} 2: 4, \mathrm{~S} 2: 6-\mathrm{S} 2: 11, \mathrm{~S} 2: 14, \mathrm{~S} 2: 17-\mathrm{S} 2: 19$.

r $S 1: 1, \mathrm{~S} 1: 2, \mathrm{~S} 1: 6, \mathrm{~S} 1: 10, \mathrm{~S} 1: 19, \mathrm{~S} 2: 5, \mathrm{~S} 2: 12, \mathrm{~S} 2: 14, \mathrm{~S} 2: 17$.

s $\mathrm{S} 1: 1, \mathrm{~S} 1: 2, \mathrm{~S} 1: 4, \mathrm{~S} 1: 5, \mathrm{~S} 1: 8, \mathrm{~S} 1: 11, \mathrm{~S} 1: 16, \mathrm{~S} 1: 18, \mathrm{~S} 1: 20, \mathrm{~S} 2: 3, \mathrm{~S} 2: 5, \mathrm{~S} 2: 7, \mathrm{~S} 2: 12, \mathrm{~S} 2: 13, \mathrm{~S} 2: 15, \mathrm{~S} 2: 19$

t $\mathrm{S} 1: 2, \mathrm{~S} 1: 4, \mathrm{~S} 1: 16, \mathrm{~S} 1: 17, \mathrm{~S} 2: 13, \mathrm{~S} 2: 17$.

the bees. In consequence, the above-mentioned pollen quantification potential could be tentatively attributed to the different electrical responses that are expected to occur when lipid/polymer membranes are exposed to solutions containing different levels and types of electrolytes (e.g., phenolic compounds and organic acids) and/or non-electrolytes (e.g., sugars) chemical compounds, although the underlying mechanisms are not fully known [37]. Electrolytes substances interact electrically with the lipid/polymer membrane inducing a change in the membrane potential $[38,39]$. Non-electrolytes compounds, containing hydroxyl groups, may interact with carboxyl or phosphate groups of the lipid/polymer membrane surface, through hydrogen bonds or due to the presence of some mediating electrolyte substances $[36,37,49,50]$.

\subsubsection{E-tongue potentiometric signals}

For each honey sample analyzed, 40 potentiometric signals
(20 different sensor membranes used in duplicate: S1:1-S1:20 and S2:1-S2:20) were recorded. Fig. 3 shows three examples of the potentiometric signals recorded by each sensor regarding the analysis of two honey samples containing minimum and maximum relative percentage abundance of Lavandula sp. pollen, for white, amber and dark honeys (in Supplementary material section, Figs. S1 to S3 show the signals profiles for all the 8 main pollens identified in the Portuguese honeys evaluated, for each honey color group). These figures show that, in general, for honeys belonging to a color group and containing a specific type of pollen, the E-tongue sensors would give potentiometric signals with different intensities depending on the relative percentage abundance of the pollen under evaluation, although with a similar overall profile. This means that, theoretically, it could be possible to use the E-tongue signals profiles to estimate the pollen percentage in a honey sample. Also, it can be seen that, in 

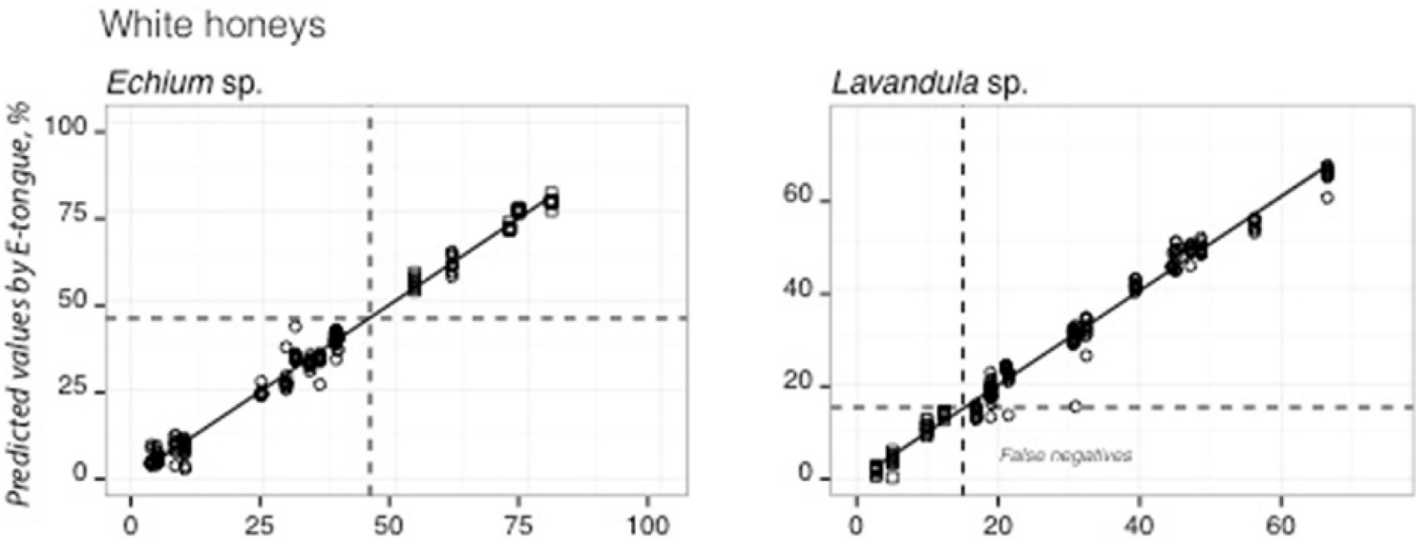

\section{Amber honeys}
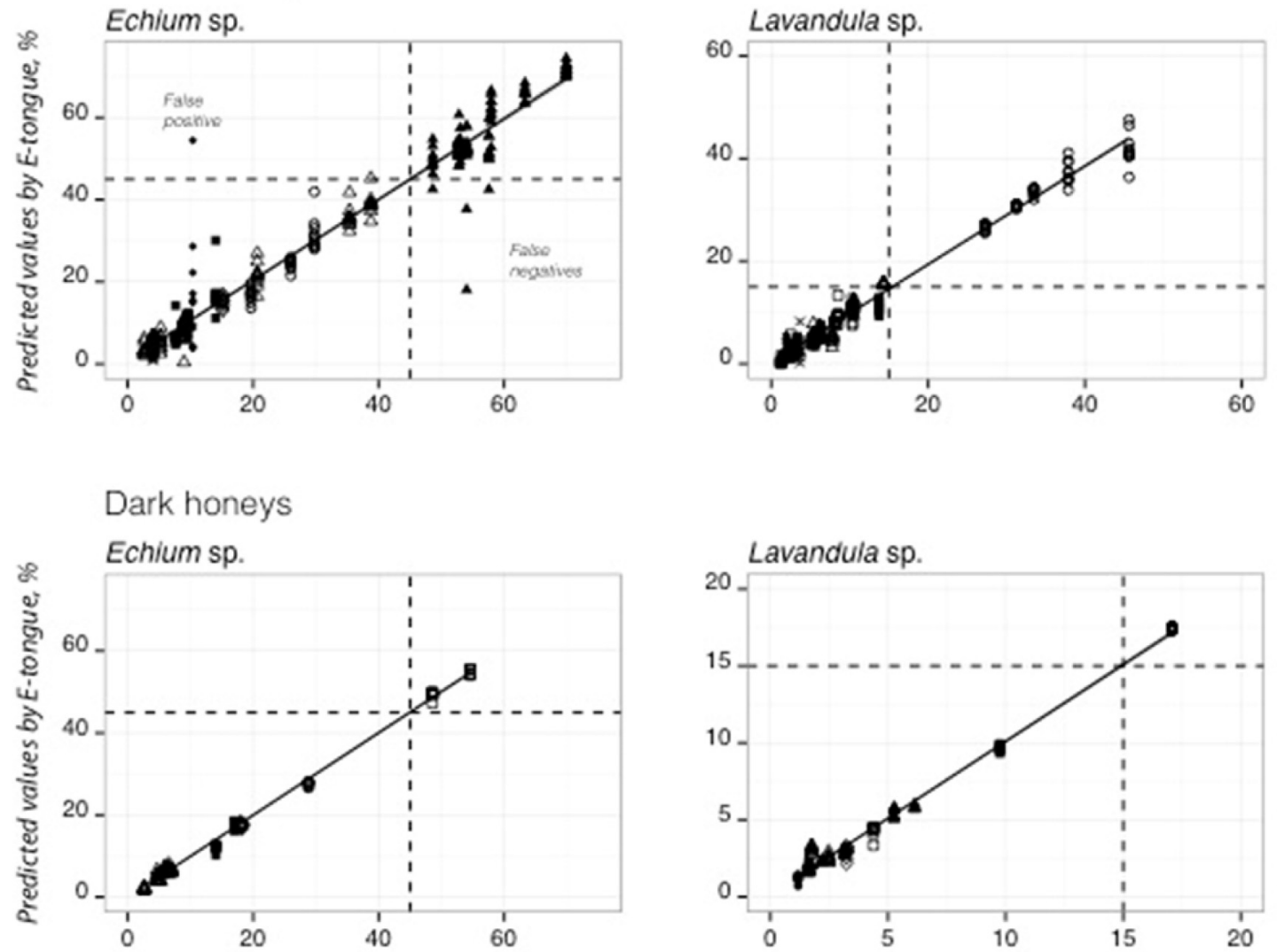

Experimental values from melissopalynology analysis, $\%$

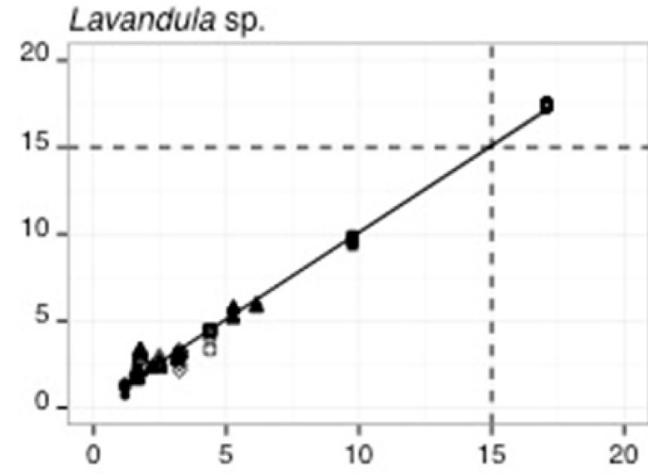

Experimental values from melissopalynology analysis, \%
- Castanea sp.
- Echium sp.
- Erica sp.
$\times$ Eucaliptus sp.
- Lavandula sp.
$\triangle$ Polyfloral
$\checkmark$ Prunus sp.
- Rubus sp.
- Trifolium sp.

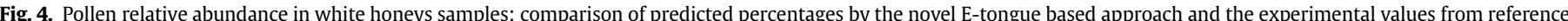

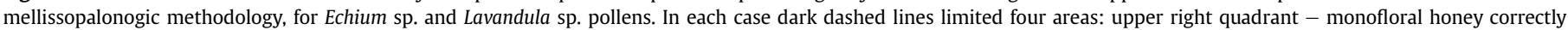

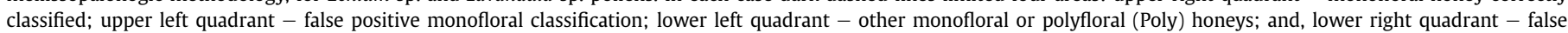
negative monofloral classification.

general, similar signal profiles are observed with the two multisensor systems (S1:1-S1:20 vs. S2:1-S2:20). Globally, signals intensities varied from $+0.090 \mathrm{~V}$ to $+0.225 \mathrm{~V}$ for all sensors included in the E-tongue, avoiding the need of data scaling.
However, the narrow range of signals intensities requires the implementation of a variable selection procedure to select the most informative signals sub-sets for establishing powerful predictive MLR models [45]. 


\subsubsection{E-tongue quantitative evaluation of honey pollen profile and} application to honey floral origin classification

The potential of proposed method was evaluated using the 74 monofloral and 15 polyfloral honeys included in the studied set. Pollen relative percentage abundance was estimated using the most informative sub-sets of sensors of the E-tongue, selected by the SA algorithm, which were used to establish MLR models. The predictive performance of each model, regarding the estimation of pollen relative percentage abundance within each honey color group, was assessed by applying the repeated K-folds crossvalidation procedure, which is a more robust technique compared with the usual LOO-CV procedure allowing minimizing the risk of overoptimistic modeling performance [46]. The results (Table 3) showed that the E-tongue based methodology is an accurate tool (average $R^{2} \geq 0.91 \pm 0.15$ for the MLR models) enabling the quantification of the relative percentage of the main pollens (Castanea sp., Echium sp., Erica sp., Lavandula sp., Prunus sp., Rubus sp. and Trifolium sp.) identified in Portuguese honeys, when present in a specific honey sample. Also, for all pollens and color groups (except for two cases: amber samples containing pollen of Lavandula sp. or Trifolium sp.), the slope and intercept values, as well as the respective $95 \%$ confidence intervals, demonstrate the quite satisfactory accuracy of the MLR models since, at 5\% significance level, the referred regression parameters are not statistically different from the theoretical expected values (slope equal to one; intercept equal to zero). So, the novel E-tongue/MLR-SA approach may be seen as a possible quantification procedure for assessing the relative pollen percentage abundance in honey samples. Indeed a satisfactory agreement is observed when representing E-tongue predicted pollen percentages vs. relative pollen abundance (\%) determined from melissopalynology analysis, which is assumed as the reference methodology for pollinic profile assessment (Fig. 4 and Figs. S4 to S6 of Supplementary material section). Nevertheless, it should be noticed that only in few cases unreal pollen relative percentages (negative values) are predicted by the MLR models. However, this unrealistic behavior is only observed for low pollen percentages (usually lower than 5-10\%) and mainly for the quantification of Prunus sp. or Rubus sp. relative percentages in amber honeys. Even so, this potential drawback does not severely affect floral origin honey classification, as can be verified from Fig. 4 (and Figs. S4 to S6). Indeed, the majority of the honey samples could be correctly classified as monofloral or polyfloral honeys based on the predicted values from the MLR models. In fact, in general, honey samples classified as a specific monofloral honey (according to the melissopalynology assays) lied in the upper right quadrant, which corresponds to the correct floral origin classification area. Yet, for a few honey samples, the MLR models gave false negative monofloral predictions (data located in the lower right quadrant delimitated by the dark dashed lines within each figure) and in only one case (amber honey containing Echium sp.) a false positive monofloral predicted classification was observed. The misclassifications were mainly observed for honey samples containing a pollen relative abundance of the same magnitude of the minimum pollen percentage required for monofloral classification. Indeed, it should be noticed that a honey sample to be classified as monofloral requires a minimum specific pollen abundance of $45 \%$ (Echium sp., Erica sp., Eucaliptus sp., Prunus sp. or Rubus sp.), 70\% (Trifolium sp.) or $90 \%$ (Castanea sp.), with the exception of Lavandula sp., for which an abundance of $15 \%$ is sufficient [51-54].

\section{Conclusions}

This work investigated the possibility of applying an E-tongue to quantify the relative percentage abundance of main pollens (Castanea sp., Echium sp., Erica sp., Lavandula sp., Prunus sp., Rubus sp. or
Trifolium sp.) identified in Portuguese monofloral and polyfloral honeys. For that, MLR models were established for each honey color group (white, amber or dark) based on sub-sets of potentiometric signals set using a SA variable selection algorithm. This study aimed to compare the predicted pollen percentages by the novel proposed E-tongue/MLR-SA approach with the experimental pollen profile data from the reference melissopalynological analysis. The results demonstrate, for the first time, that the proposed analytical approach could be a complementary tool to the traditional timeconsuming pollinic analysis, enabling a preliminary pollinic honey evaluation. Nevertheless, further studies must be carried out to overcome some drawbacks, namely the misclassification of some monofloral honeys (cases of false negative classifications) and the unreal percentage values (negative values) obtained for honeys containing low pollen relative percentages. For such studies, new honey samples with a lower variability in pollinic composition, will be required, to understand the differences of the underlying behaviors of the potentiometric E-tongue. However, it has been showed that there exists a relation between pollen abundance in a honey sample and the potentiometric signals profiles recorded, which could be tentatively related with organoleptic attributes of each honey studied.

\section{Acknowledgments}

This work was co-financed by FCT/MEC and FEDER under Programme PT2020 (Project UID/EQU/50020/2013); and under the strategic funding of UID/BIO/04469/2013 unit.

\section{Appendix A. Supplementary data}

Supplementary data related to this article can be found at http:// dx.doi.org/10.1016/j.aca.2015.10.014.

\section{References}

[1] S. Gomes, L.G. Dias, L.L. Moreira, P. Rodrigues, L. Estevinho, Physicochemical, microbiological and antimicrobial properties of commercial honeys from Portugal, Food Chem. Toxicol. 48 (2010) 544-548.

[2] J.S. Lazarevic, R.M. Palic, N.S. Radulovic, N.R. Ristic, G.S. Stojanovic, Chemical composition and screening of the antimicrobial and antioxidative activity of extracts of Stachys species, J. Serb. Chem. Soc. 75 (2010) 1347-1359.

[3] L.B. Almeida-Muradian, K.M. Stramm, A. Horita, O.M. Barth, A.S. Freitas, L.M. Estevinho, Comparative study of the physicochemical and palynological characteristics of honey from Melipona subnitida and Apis mellifera, Int. J. Food Sci. Tech. 48 (2013) 1698-1706.

[4] L.C. Marchini, V.D.A. Reis, A.C.C.C. Moreti, Composição físico-química de amostras de pólen coletado por abelhas africanizadas Apis mellífera (Hymenoptera: Apidae) em Piracicaba, estado de São Paulo, Cienc. Rural. 36 (2006) 949-953.

[5] L. Castro-Vázquez, M.C. Díaz-Maroto, C. de Torres, M.S. Pérez-Coello, Effect of geographical origin on the chemical and sensory characteristics of chestnut honeys, Food Res. Int. 43 (2010) 2335-2340.

[6] S. Stolzenbach, D.V. Byrne, W.L.P. Bredie, Sensory local uniqueness of Danish honeys, Food Res. Int. 44 (2011) 2766-2774.

[7] A. Iglesias, X. Feás, S. Rodrigues, J.A. Seijas, M.P. Vázquez-Tato, L.G. Dias L.M. Estevinho, Comprehensive study of honey with protected denomination of origin and contribution to the enhancement of legal specifications, Molecules 17 (2012) 856-8577.

[8] A. Moussa, D. Noureddine, A. Saad, M. Abdelmalek, B. Salima, The influence of botanical origin and physico-chemical parameters on the antifungal activity of algerian honey, Plant Pathol. Microbiol. 3 (2012) 132, 5pp.

[9] E. Olga, F.-G. María, S.M. Carmen, Differentiation of blossom honey and honeydew honey from northwest spain, Agriculture 2 (2012) 25-37.

[10] V.M. Bryant Jr., Pollen contents of honey, Can. Assoc. Palynol. Newsl. 24 (2001) $10-24$.

[11] A. Salonen, T. Ollikka, E. Grönlund, L. Ruottinen, R. Julkunen-Tiitto, Pollen analyses of honey from Finland, Grana 48 (2009) 281-289.

[12] F. Corvucci, L. Nobili, D. Melucci, F.-V. Grillenzoni, The discrimination of honey origin using melissopalynology and Raman spectroscopy techniques coupled with multivariate analysis, Food Chem. 169 (2015) 297-304.

[13] M.E.B.C. Sousa, L.G. Dias, A.C.A. Veloso, L. Estevinho, A.M. Peres, A.A.S.C. Machado, Practical procedure for discriminating monofloral honey with abroad pollen profile variability using an electronic tongue, Talanta 128 
(2014) 284-292.

[14] I. Escriche, M. Kadar, E. Domenech, L. Gil-Sánchez, A potentiometric electronic tongue for the discrimination of honey according to the botanical origin. Comparison with traditional methodologies: physicochemical parameters and volatile profile, J. Food Eng. 109 (2012) 449-456.

[15] I. Escriche, M. Kadar, M. Juan-Borrás, E. Domenech, Suitability of antioxidant capacity, flavonoids and phenolic acids for floral authentication of honey. Impact of industrial thermal treatment, Food Chem. 142 (2014) 135-143.

[16] G. Scandurra, G. Tripodi, A. Verzera, Impedance spectroscopy for rapid determination of honey floral origin, J. Food Eng. 119 (2013) 738-743.

[17] M.I. Isla, A. Craig, R. Ordoñez, C. Zampini, J. Sayago, E. Bedascarrasbure, A. Alvarez, V. Salomón, L. Maldonado, Physico chemical and bioactive properties of honeys from Northwestern Argentina, LWT-Food Sci. Technol. 44 (2011) 1922-1930.

[18] O. Escuredo, L.R. Silva, P. Valentão, M.C. Seijo, P.B. Andrade, Assessing Rubus honey value: pollen and phenolic compounds content and antibacterial capacity, Food Chem. 130 (2012) 671-678.

[19] J.M. Alvarez-Suarez, S. Tulipani, D. Díaz, Y. Estevez, S. Romandini, F. Giampieri, E. Damiani, P. Astolfi, S. Bompadre, M. Battino, Antioxidant and antimicrobia capacity of several monofloral Cuban honeys and their correlation with color, polyphenol content and other chemical compounds, Food Chem. Toxicol. 48 (2010) 2490-2499.

[20] M.M. Özcan, Ç. Ölmez, Some qualitative properties of different monofloral honeys, Food Chem. 163 (2014) 212-218.

[21] I. Jerković, P.M. Kuś, C.I.G. Tuberoso, M. Šarolić, Phytochemical and physical-chemical analysis of Polish willow (Salix spp.) honey: identification of the marker compounds, Food Chem. 145 (2014) 8-14.

[22] P.M. Kuś, F. Congiu, D. Teper, Z. Sroka, I. Jerković, C.I.G. Tuberoso, Antioxidant activity, color characteristics, total phenol content and general HPLC fingerprints of six Polish unifloral honey types, LWT-Food Sci. Technol. 55 (2014) $124-130$

[23] M.L. Al, D. Daniel, A. Moise, O. Bobis, L. Laslo, S. Bogdanov, Physico-chemical and bioactive properties of different floral origin honeys from Romania, Food Chem. 112 (2009) 863-867.

[24] M. Viuda-Martos, Y. Ruiz-Navajas, J.M. Zaldivar-Cruz, V. Kuri, J. FernándezLópez, Á.A. Carbonell-Barrachina, J.Á. Pérez-Álvarez, Aroma profile and physico-chemical properties of artisanal honey from Tabasco, Mexico, Int. J. Food Sci. Tech. 45 (2010) 1111-1118.

[25] USDA Agricultural Marketing Service, United States Standards for Grades of Extracted Honey, USDA, Washington DC, May 23, 1985.

[26] N. Major, K. Marković, M. Krpan, G. Šarić, M. Hruškar, N. Vahčić, Rapid honey characterization and botanical classification by an electronic tongue, Talanta 85 (2011) 569-574.

[27] L.A. Dias, A.M. Peres, M. Vilas-Boas, M.A. Rocha, L. Estevinho, A.A.S.C. Machado, An electronic tongue for honey classification, Microchim. Acta 163 (2008) 97-102.

[28] Z. Wei, J. Wang, W. Liao, Technique potential for classification of honey by electronic tongue, J. Food Eng. 94 (2009) 260-266.

[29] A. Zakaria, A.Y. Md Shakaff, M.J. Masnan, M.N. Ahmad, A.H. Adom, M.N. Jaafar, S.A. Ghani, A.H. Abdullah, A.H.A. Aziz, L.M. Kamarudin, N. Subari, N.A. Fikri, A biomimetic sensor for the classification of honeys of different floral origin and the detection of adulteration, Sensors 11 (2011) 7799-7822.

[30] E. Garcia-Breijo, J. Garrigues, L.G. Sanchez, N. Laguarda-Miro, An embedded simplified fuzzy ARTMAP implemented on a microcontroller for food classification, Sensors 13 (2013) 10418-10429.

[31] I.C.F.R. Ferreira, E. Aires, J.C.M. Barreira, L.M. Estevinho, Antioxidant activity of Portuguese honey samples: different contributions of the entire honey and phenolic extract, Food Chem. 114 (2009) 1438-1443.

[32] J. Louveaux, A. Maurizio, G. Vorwohl, Methods of melissopalynology, Bee World 59 (1978) 139-157.
[33] L.A. Dias, A.M. Peres, A.C.A. Veloso, F.S. Reis, M. Vilas-Boas, A.A.S.C. Machado, An electronic tongue taste evaluation: identification of goat milk adulteration with bovine milk, Sensors Actuat. B-Chem. 136 (2009) 209-217.

[34] Y. Kobayashi, M. Habara, H. Ikezazki, R. Chen, Y. Naito, K. Toko, Advanced taste sensors based on artificial lipids with global selectivity to basic taste qualities and high correlation to sensory scores, Sensors 10 (2010) 3411-3443.

[35] M. Habara, D. Beppu, H. Cui, H. Ikeazaki, K. Toko, Detection of sugars using lipid/polymer membranes, Sensors Mater 19 (2011) 325-331.

[36] K. Toyota, H. Cui, K. Abe, M. Habara, K. Toko, H. Ikeazaki, Sweetness sensor with lipid/polymer membranes: sweet-responsive substances, Sensors Mater 23 (2011) 465-474.

[37] K. Toyota, H. Cui, K. Abe, M. Habara, K. Toko, H. Ikeazaki, Sweetness sensor with lipid/polymer membranes: response to various sugars, Sensors Mater 23 (2011) 475-482.

[38] M. Yasuura, H. Okazaki, Y. Tahara, H. Ikezaki, K. Toko, Development of sweetness sensor with selectivity to negatively charged high-potency sweeteners, Sensors Actuat. B-Chem. 201 (2014) 329-335.

[39] M. Yasuura, Y. Tahara, H. Ikezaki, K. Toko, Development of a sweetness sensor for aspartame, a positively charged high-potency sweetener, Sensors 14 (2014) 7359-7373.

[40] J. Cadima, J.O. Cerdeira, M. Minhoto, Computational aspects of algorithms for variable selection in the context of principal components, Comput. Stat. Data Anal. 47 (2004) 225-236.

[41] J. Cadima, J.O. Cerdeira, P.D. Silva, M. Minhoto, The Subselect R Package, 2012. http://cran.r-project.org/web/packages/subselect/vignettes/subselect.pdf.

[42] M. Gendreau, J. Potvin, Handbook of Metaheuristics, International Series in Operations Research \& Management Science vol. 146, Springer, New York, 2010.

[43] J.M. Gutiérrez, Z. Haddi, A. Amari, B. Bouchikhi, A. Mimendia, X. Cetó, M. del Valle, Hybrid electronic tongue based on multisensor data fusion for discrimination of beers, Sensors Actuat. B-Chem. 177 (2013) 989-996.

[44] L.G. Dias, A. Fernandes, A.C.A. Veloso, A.A.S.C. Machado, J.A. Pereira, A.M. Peres, Single-cultivar extra virgin olive oil classification using a potentiometric electronic tongue, Food Chem. 160 (2014) 321-329.

[45] L.G. Dias, C. Sequeira, A.C.A. Veloso, M.E.B.C. Sousa, A.M. Peres, Evaluation of healthy and sensory indexes of sweetened beverages using an electronic tongue, Anal. Chim. Acta 848 (2014) 32-42.

[46] M. Kuhn, K. Johnson, Applied Predictive Modeling, Springer Science + Business Media, 2013. New York, USA.

[47] L.G. Dias, A.M. Peres, T.P. Barcelos, J. Sá Morais, A.A.S.C. Machado, Semiquantitative and quantitative analysis of soft drinks using an electronic tongue, Sensors Actuat. B-Chem. 154 (2011) 111-118.

[48] W.N. Venables, B.D. Ripley, Modern Applied Statistics with S, fourth ed., Springer, New York, USA, 2002.

[49] S. Ishizaka, S. Kinoshita, Y. Nishijima, N. Kitamura, Direct observation of molecular recognition mediated by triple hydrogen bonds at a water/oil interface: time-resolved total internal reflection fluorometry study, Anal. Chem. 75 (2003) 6035-6042.

[50] S. Nishizawa, T. Yokobori, R. Kato, K. Yoshimoto, T. Kamaishi, N. Teramae, Hydrogen-bond forming ionophore for highly efficient transport of phosphate anions across the nitrobenzene-water interface, Analyst 128 (2003) 663-669.

[51] L.P. Oddo, M.G. Piazza, A.G. Sabatini, M. Accorti, Characterization of unifloral honeys, Apidologie 26 (1995) 453-465.

[52] L.P. Oddo, R. Piro, Main European unifloral honeys: descriptive sheets, Apidologie 35 (2004) 38-81.

[53] W. von der Ohe, L.P. Oddo, M.L. Piana, M. Morlot, P. Martin, Harmonized methods of meliassopalynology, Apidologie 35 (2004) 18-25.

[54] M.G. Piazza, L.P. Oddo, Bibliographical review of the main European unifloral honeys, Apidologie 35 (2004) 94-111. 